\title{
THE EFFECT OF VARIOUS SILICATE-GLASS MATRIXES ON GOLD-NANOPARTICLE FORMATION
}

\author{
"BLANKA SVECOVA*, PAVLA NEKVINDOVA*, STANISLAV STANEK*, SONA VYTYKACOVA*, \\ ANNA MACKOVA**,***, PETR MALINSKY**, ROMANA MIKSOVA**,***, MILOS JANECEK****, \\ JOSEF PESICKA****, JARMILA SPIRKOVA* \\ *Department of Inorganic Chemistry, Faculty of Chemical Technology, University of Chemistry and Technology, \\ Technicka 5, 16628 Prague, Czech Republic \\ **Nuclear Physics Institute, Academy of Sciences of the Czech Republic, v.v.i., \\ 25068 Rez, Czech Republic \\ ***Department of Physics, Faculty of Science, J. E. Purkinje University, Ceske mladeze 8, \\ 40096 Usti nad Labem, Czech Republic \\ ****Department of Physics of Materials, Faculty of Mathematics and Physics, Charles University, \\ Ke Karlovu 5, 12116 Prague, Czech Republic \\ ${ }^{\#}$ E-mail: blanka.svecova@vscht.cz
}

Submitted June 30, 2016; accepted October 26, 2016

\begin{abstract}
Keywords: Glasses, Nano particles, Transmission electron microscopy (TEM), Ion implantation
Ion implantation of $\mathrm{Au}^{+}$with energy of $1.7 \mathrm{MeV}$ and a fluence of $1 \times 10^{16} \mathrm{ions}^{\cdot} \mathrm{cm}^{-2}$ along with post-implantation annealing were used to synthesize metal nanoparticles in various types of silicate glasses. The objective of the work was the investigation of the effect of the host glass matrix on the principle properties of the nanoparticles. The prepared samples were characterized in terms of their chemical composition and the nucleation of gold nanoparticles. The largest nanoparticles having a radius of $1-25 \mathrm{~nm}$ and an irregular shape were detected in the glass BK7 containing boron trioxide in its structure. On the other hand, small nanoparticles $(1-5 \mathrm{~nm})$ with a spherical shape were found in glass with a structure similar to silica. The shape, size and distribution of the nanoparticles are strongly influenced by the divergence of the annealing temperature from the transformation temperature of the particular glass.
\end{abstract}

\section{INTRODUCTION}

Diverse metallic precipitates have been synthesized and reported in various substrates. Numerous review articles reporting interactions between metals and substrates, such as the formation of nanoparticles, nanoparticle-composition modifications, and consequent optical-property changes have been published [1-4]. It has been shown that glasses containing the nanoparticles of copper, silver or gold are considered as prospective non-linear optical materials, because they exhibit strong non-linear third-order susceptibility $\chi^{3}$ [5-7].

Ion implantation is the most versatile method for the preparation of metal nanoparticles in silica or glasses [8-11]. This method has many advantages - in particular, it allows to control easily the depth layer and the concentration of the implanted ions, as well as the nanoparticle formation. It was found that an increase in the ion-implantation fluence and energy leads to the formation of nanoparticles and facilitates their growth. Similar effect, especially for gold nanoparticles, is achieved by post-implantation annealing [12]. The damage of the matrix in the ion-impact area and the creation of defects are disadvantages of the high-energy ion-implantation process. These defects can also cause the absorption of optical radiation in the range of $5-7 \mathrm{eV}$ $[13,14]$, but they can be eliminated by post-implantation annealing.

Besides the above-mentioned factors, the growth and the distribution of metal nanoparticles can also be influenced by the chemical composition of the glass matrix. In terms of nanoparticle formation, silica is still the most studied substrate. In this matrix, the formation of gold nanoparticles is affected by ion-implantation parameters - the threshold fluence for the spontaneous formation of gold nanoclusters in silica is $2 \times 10^{17}$ ions $\cdot \mathrm{cm}^{-2}$ for $3.0 \mathrm{MeV} \mathrm{Au}^{+}$ions [15]. Below the threshold, post-implantation annealing can be used for nanoparticle creation. The critical temperature for the formation of metal nanoparticles correlates only roughly with the bulk metal melting point [15].

The formation of metal nanoparticles in various types of silicate glass is much less understood. Moreover, a direct comparison of the glass-matrix influence on the resulting non-linear characteristics is complicated, as, the same measurement parameters have to be always maintained. So far, the baseline study has been done for example on glass with various alkali concentrations [1619]. It has been found that the content of sodium in the matrix affects the movement of the implanted ions during 
post-implantation annealing. Ion exchange was suggested as the mechanism of the movement of implanted silver ions through the glass matrix. Furthermore, studies on borate glasses have also been performed [20]. The superior optical properties of the borate glass matrix have been revealed in a slow relaxation process.

Here, we are going to build on our previous work [21], where we found that the penetration of the implanted ions is influenced by the structure of particular glass. Four representative types of glass have been selected. These glasses differ in the cross-linking degree of the glass matrix [22]. The maximum cross-linking degree is represented by silica $\left(\mathrm{A}_{500} / \mathrm{A}_{1000} \sim 9\right)$. The BK7 glass contains more components than silica glass and models the least cross-linked structure $\left(\mathrm{A}_{500} / \mathrm{A}_{1000} \sim 2\right)$. Ion implantation of $\mathrm{Au}^{+}$ions with energy of $1.7 \mathrm{MeV}$ and a fluence of $1 \times 10^{16}$ ions $\mathrm{cm}^{-2}$ along with postimplantation annealing were used to synthesize metal nanoparticles in the selected silicate glasses. The TEM analysis showed that the formed nanoparticles varied not only in the shape and the size but also in the distribution. It was also proved that boron trioxide when present in the glass structure significantly supports the nucleation of the nanoparticles (the formation of clusters), which is in good agreement with the findings concerning the coloration of glasses [23]. The utility of the Raman spectroscopy for the characterization of the changes in the structure of glass after the ion implantation was also demonstrated in our previous work [22]. Moreover, using the Z-scan technique, it can be shown that the nanoparticles produced in silicate glasses exhibit substantial two-photon absorption (TPA). We have demonstrated that the TPA coefficient differs depending on the size, the shape, and the depth distribution of the metal nanoclusters and the structure and the composition of glass substrates [24].

\section{EXPERIMENTAL}

In this study, we used several silicate glass substrates with different chemical compositions (see Table 1), namely the specially designed glass type GIL49 and the glass B (made at the Glass Institute Hradec Kralove Ltd., Czech Republic), commercially available BK7 and silica glass. The selected glass substrates varied in the concentrations and types of network formers $\left(\mathrm{SiO}_{2}\right.$, $\mathrm{B}_{2} \mathrm{O}_{3}$ ) and network modifiers (alkali oxides).
Pre-cleaned glass substrates were implanted with $\mathrm{Au}^{+}$ions at energy of $1.7 \mathrm{MeV}$ at the Tandetron accelerator in the Nuclear Physics Institute, Academy of Sciences of the Czech Republic, with an ion fluence of $1 \times 10^{16}$ ions $\mathrm{cm}^{-2}$. The as-implanted glasses were subsequently annealed in air at temperatures of $600^{\circ} \mathrm{C}$ for 5 hours.

The concentration depth profiles of the implanted atoms were analyzed by Rutherford Backscattering Spectrometry (RBS) using a $2.0 \mathrm{MeV} \mathrm{He}^{+}$ion beam. The incoming angle of the ions during the RBS analysis was $0^{\circ}$, while the backscattered ions were detected under a scattering angle of $170^{\circ}$. The simulated profiles of the implants were provided by the SRIM 2008 code [25]. RBS analysis makes it possible to achieve a depth resolution better than $10 \mathrm{~nm}$. The sensitivity of the analysis in this particular case was about 0.5 atomic $\%$.

The properties of the nanoparticles were studied with Transmission Electron Microscopy (TEM) using a JEOL $2000 \mathrm{FX}$ operated at $200 \mathrm{kV}$ and equipped with a Link AN 10000 energy dispersive X-ray analyser (EDAX). Thin foils of the glass samples for the TEM analysis were prepared by a special thinning process using a dimple grinder and a precision ion polishing system 'PIPS' (by Gatan Inc.). The size distribution of nanoparticles was determined from TEM micrographs.

\section{RESULTS}

The characterization of the distribution of Au ions in the as-implanted samples

The concentration depth profiles of the implanted $\mathrm{Au}^{+}$ions were measured using the RBS method and compared to the simulated Au depth profiles by SRIM 2008. The parameters characterizing $\mathrm{Au}$ distribution in glass obtained from the experimental depth profiles (supposing Gaussian distribution, we extracted the mean value $R_{P}$ and the standard deviation $\Delta R_{P}$ ) are shown in Table 2 , in addition to the density $\rho$ and the molar-volume $V_{m}$ values for the pertinent type of glass. It is evident that under the above-mentioned implantation conditions, the gold particles were distributed in a subsurface layer of the approximate thickness of $110 \mathrm{~nm}$. The maximum $\mathrm{Au}$ concentration $(0.5$ at. $\%)$ was found at a depth around $570 \mathrm{~nm}$, see the $\mathrm{Au}$ implantation depth profile in the silica glass in Figure 1.

In Table 2, we can see that the mean value $R_{P}$ is

Table 1. The composition of used glasses (at. \%)

\begin{tabular}{lccccc}
\hline Type of glass & $\mathrm{SiO}_{2}$ & $\mathrm{~B}_{2} \mathrm{O}_{3}$ & $\mathrm{Na}_{2} \mathrm{O}$ & $\mathrm{K}_{2} \mathrm{O}$ & Other components \\
\hline BK7 & 58 & 18 & 14 & 9 & $\mathrm{As}_{2} \mathrm{O}_{3}, \mathrm{BaO}$ \\
GIL49 & 63 & - & 24 & 0.5 & $\mathrm{Al}_{2} \mathrm{O}_{3}, \mathrm{CaO}_{2} \mathrm{MgO}^{-}$ \\
Glass B & 88 & - & 9 & - & $\mathrm{Al}_{2} \mathrm{O}_{3}$ \\
Silica glass & 100 & - & - & - & - \\
\hline
\end{tabular}




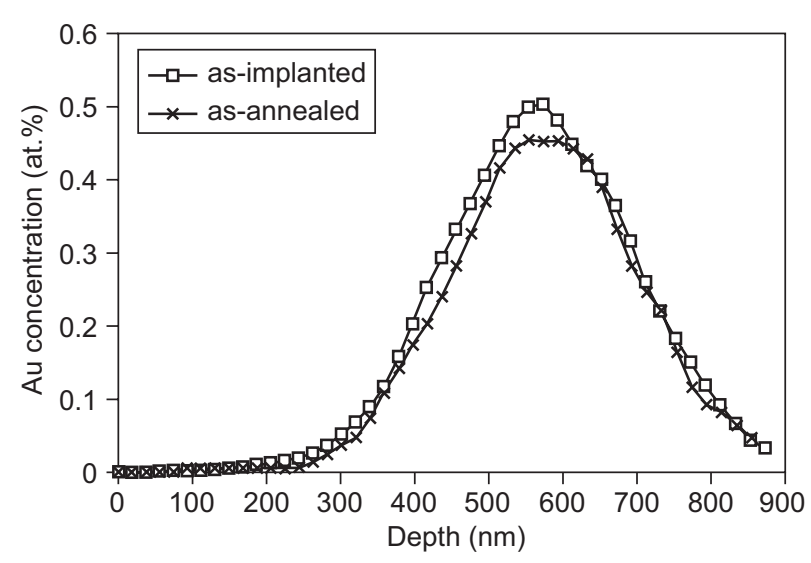

Figure 1. The concentration depth profile of $\mathrm{Au}$ in silicate glasses; $\mathrm{Au}^{+}$ions implanted with energy of $1.7 \mathrm{MeV}$ and a fluence of $1 \times 10^{16}$ ions $\cdot \mathrm{cm}^{-2}$ (the squares) and then annealed at $600^{\circ} \mathrm{C}, 5 \mathrm{~h}$ (the crosses).

related to glass density, i.e., the lower $R_{P}$ value was found in the glass with higher density. This trend is in accordance with the SRIM simulation, although the experimentally determined parameters, $R_{P}$ and $\Delta R_{P}$, are higher than the simulated parameters (about $10 \%$ for glass GIL49 and for $20-30 \%$ in case of other glasses). The experimentally determined broader dopant distribution is often observed in case, when the ions penetrating the solid-state material have the higher experimental energy straggling than the simulated ones. This fact is connected to possible non-homogeneity of the glass and/or ion modified structure of the glass matrix that can influence the penetration depth in real samples. A similar, but not so significant, effect has also been observed in glasses implanted with $\mathrm{Ag}^{+}$ions [21, 27].

Good agreement between growing trends of the

Table 2. A comparison of the $R_{P}$ and $\Delta R_{P}$ values obtained from the profiles measured by RBS and extrapolated by the Gaussian function in various types of glass, for which the densities $\rho$ and the molar volumes $V_{m}$ are also shown.

\begin{tabular}{lcccc}
\hline Type of glass & $\begin{array}{c}\rho \\
{\left[\mathrm{g} \cdot \mathrm{cm}^{-3}\right]}\end{array}$ & $\begin{array}{c}V_{\mathrm{m}} \\
{\left[\mathrm{cm}^{3} \cdot \mathrm{mol}^{-1}\right]}\end{array}$ & $R_{P}[\mathrm{~nm}]$ & $\Delta R_{P}[\mathrm{~nm}]$ \\
\hline GIL49 & 2.49 & 23.8 & 421 & 102 \\
BK7 & 2.50 & 25.7 & 482 & 112 \\
Glass B & 2.32 & 26.3 & 560 & 117 \\
Silica glass & 2.20 & 27.3 & 569 & 128 \\
\hline
\end{tabular}

molar-volume values and the projected ranges of the implanted $\mathrm{Au}^{+}$ions is shown in Table 2. It is obvious that not only the glass density, but also other factors influence the projected range of the implanted ions. A significant correlation of the projected ranges with the structure of glass as well as with the strength of the chemical bonds in the glass structure can be expected.

Concerning the nucleation of gold nanoparticles in glasses after the ion implantation, no absorption bands in the UV-VIS region indicating the nanoparticle inherency have been observed between 415 and $560 \mathrm{~nm}$ at any type of the as-implanted glass substrates.

We have also simulated the defect evolution caused by the gold implantation into the glass matrix by the SRIM code. There are two known mechanisms of defect creation: (i) electronic excitation and (ii) nuclear collision. The former mechanism leads to the excitation and ionization of molecules and consequently to the formation of a large number of mobile radical species. Nuclear collisions are accompanied by a massive breakage of chemical bonds due to the displacement of atomic nuclei, and by a transfer of rather high energy to the glass matrix in the form of phonons. In our case, both mechanisms act simultaneously and their additive contribution to the total energy losses of the incoming ion is characterized by the stopping power $\left(S_{\mathrm{e}}\right.$ for the electronic mechanism and $S_{\mathrm{n}}$ for the nuclear one, respectively), which represents the change in the energy

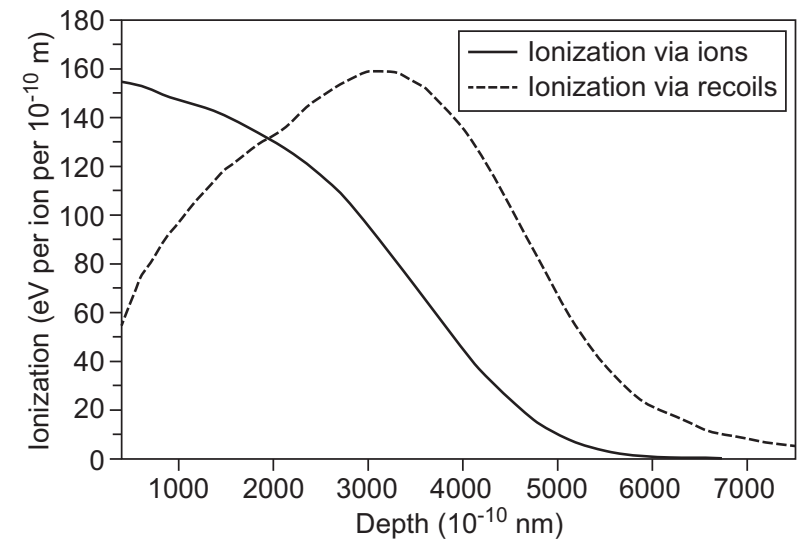

a)

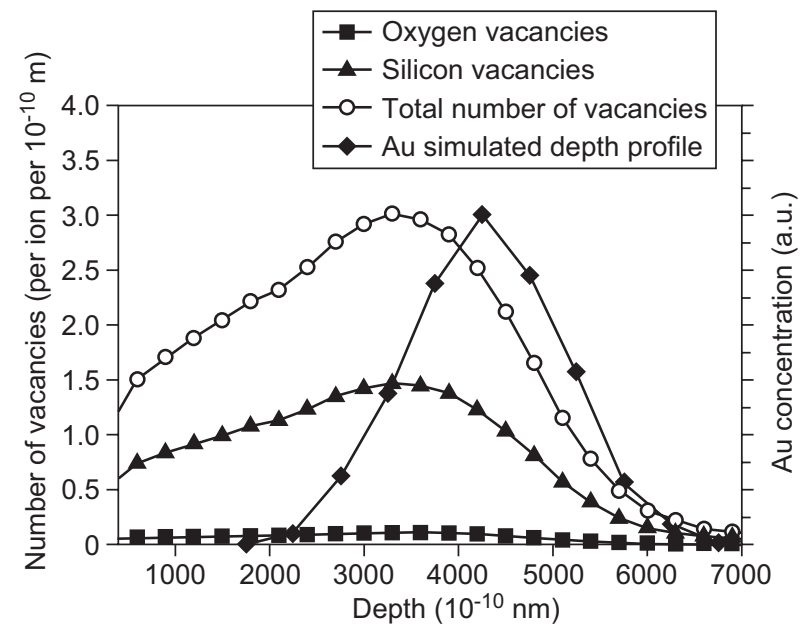

b)

Figure 2. SRIM simulations of $\mathrm{SiO}_{2}$ implanted by $1.7 \mathrm{MeV} \mathrm{Au}^{+}$ ions; a) Comparison of energy losses via electronic stopping (ionization of the target atoms) and nuclear stopping (recoiling of target atoms); b) Number of displaced atoms (vacancies) produced per $1 \AA\left(10^{-10} \mathrm{~m}\right)$ depending on the depth. 
of ion caused by its interaction with the glass matrix per path length and is usually expressed in $\mathrm{eV} / \AA$. The values of $S_{\mathrm{e}}$ and $S_{\mathrm{n}}$ depend on the energy and the mass of the implanted ion as well as on the glass composition, with the energetic light ions depositing the energy mainly via electronic excitations and the energy transfer from low-energy heavy ions being realized predominantly by nuclear collisions. As the implanted ion slows down, the contribution of each mechanism to the overall energy loss substantially changes. The depth distribution of glass target ionization via the implanted ions and via the recoiled matrix atoms are presented for $\mathrm{Au}^{+}, 1.7 \mathrm{MeV}$ in $\mathrm{SiO}_{2}$ in Figure 2a. The production of total displaced atoms, oxygen and silicon vacancies produced per one ion at a length of $1 \AA$ is also depicted (see Figure $2 b$ ). It is clear that the energy losses in glasses implanted with $\mathrm{Au}$ ions occur mainly via nuclear stopping (e.g. for silica glass, the ratio $S_{\mathrm{e}} / S_{\mathrm{n}}$ is about 0.6 ). It can be seen that $\mathrm{Au}$ ions cause prevailing number of $\mathrm{Si}$ vacancies and defects during recoiling of the host matrix atoms in the implanted layer. When the creation of defects was simulated in other glasses, no significant differences were found. In all glasses, the mechanism of nuclear collisions was predominant and the depth of damage was equivalent to the measured concentration profile of $\mathrm{Au}$.

\section{The characterization of Au particles in the as-annealed samples}

After $\mathrm{Au}^{+}$ion implantation, all of the types of investigated silicate glass were annealed under the same conditions, i.e., for 5 hours at $600^{\circ} \mathrm{C}$, in the ambient atmosphere. The temperature of annealing was chosen according to our previous study of the annealing of the glass GIL49 [26]. Using that temperature, the GIL49 glass became stained red, which indicated the presence of the gold nanoparticles in the glass specie. On the other hand, at lower temperatures, no colors were observed, whereas higher temperatures induced damage to the glass matrix.

The change of the concentration depth profile in silica glass is shown in Figure 1. After five hours of annealing at $600^{\circ} \mathrm{C}$, no significant shift of the concentration profile was noticed. The integral amount of gold slightly decreased after post-implantation annealing (by $7 \%$ ). In other glass matrixes, the shifts of the $\mathrm{Au}$ concentration maximum remained negligible (max. $40 \mathrm{~nm}$ ) and also the change of the integral amount was below the detection limit of the RBS method.

The color of the glass samples changed during the annealing from colorless to red, as well as the measured absorption spectra [24], indicating gold nanoparticle formation. An evaluation of the size, the shape and the distribution of the nanoparticles was performed by TEM. Three types of the as-annealed samples showing substantial absorption in the UV-VIS region were exa- mined. The TEM analysis of the silica glass was not performed, because the glass did not become red after annealing; as no absorption in the UV-VIS region was detected in this glass, we assumed that no gold nanoparticles were created. In other glasses, however, the nanoparticles were apparently formed. The TEM images are shown in Figure 3, where the bright areas in the micrograph represent the glass while the dark dots represent the nanoparticles of gold. The depth of the maximum $\mathrm{Au}$ concentration determined from RBS is in good agreement with the depth at which nanoparticles were observed by TEM, see Figure 3 (left panels).

The statistical distribution of the Au-nanoparticle size in the mentioned glass types was provided using the image processing procedure [28] and is presented in Figure 3 (right panels). It is clear that the size and the shape of nanoparticles in various glass types are different, although the preparation conditions remained unchanged. The largest nanoparticles with an average diameter ranging from 1 to $25 \mathrm{~nm}$ were noticed in the glass BK7.

On the other hand, small nanoparticles (1-5 nm) were found in the glass B. The nanoparticles observed in the glass B and glass GIL49 had a spherical shape, whereas the nanoparticles observed in the glass BK7 had an irregular shape, cf. Figure 3 left. Moreover, the smallest nanoparticles observed in the glass B were distributed in a relatively broad layer of $350 \mathrm{~nm}$ while the largest nanoparticles in the glass BK7 were confined to a narrow layer of approximately $100 \mathrm{~nm}$ thick.

\section{DISCUSSION}

A comparison of the concentration depth profiles of $\mathrm{Au}$ implanted into various types of glass has shown that $\mathrm{Au}^{+}$ion range depends primarily on the density of the glass matrix. The asymmetrical shape of the same Au-concentration depth profile is a consequence of local changes in glass density caused by ion implantation [14, 22]. It may also explain why the measured concentration depth profile differed from the SRIM simulation, which does not include the non-homogeneity of the glass or local structural changes caused by the ion implantation.

The defects caused mainly by the mechanism of nuclear collisions in the implanted layer, as well as their subsequent healing, are likely to differ in various glasses. A simulation of these small differences is impossible. More about this issue is suggested in our detailed study of Raman spectra which were scanned at various layer depths (see [22]). The dissimilar degree of depolymerization mainly in silica glass as compared to glass containing boron, as well as the different behavior of glass matrixes during post-implantation annealing was noticeable.

The different extent of the healing of the glass structure during annealing may be consistent with 

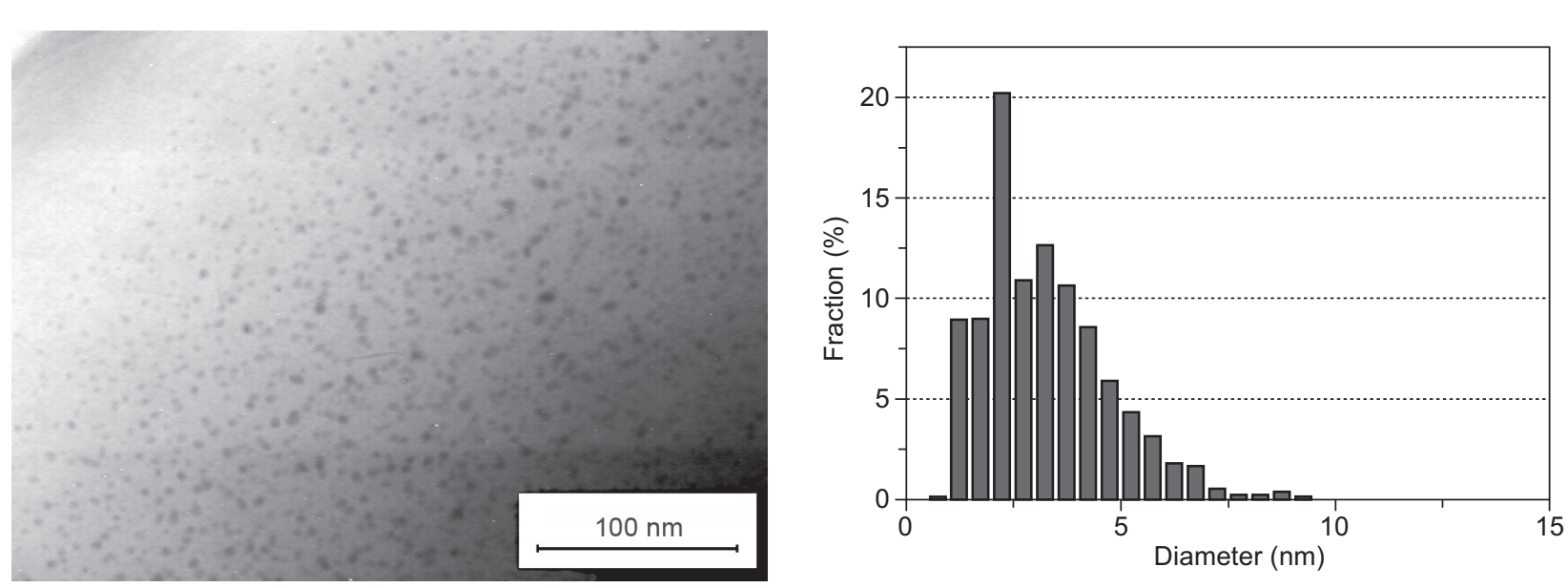

a) glass $B$
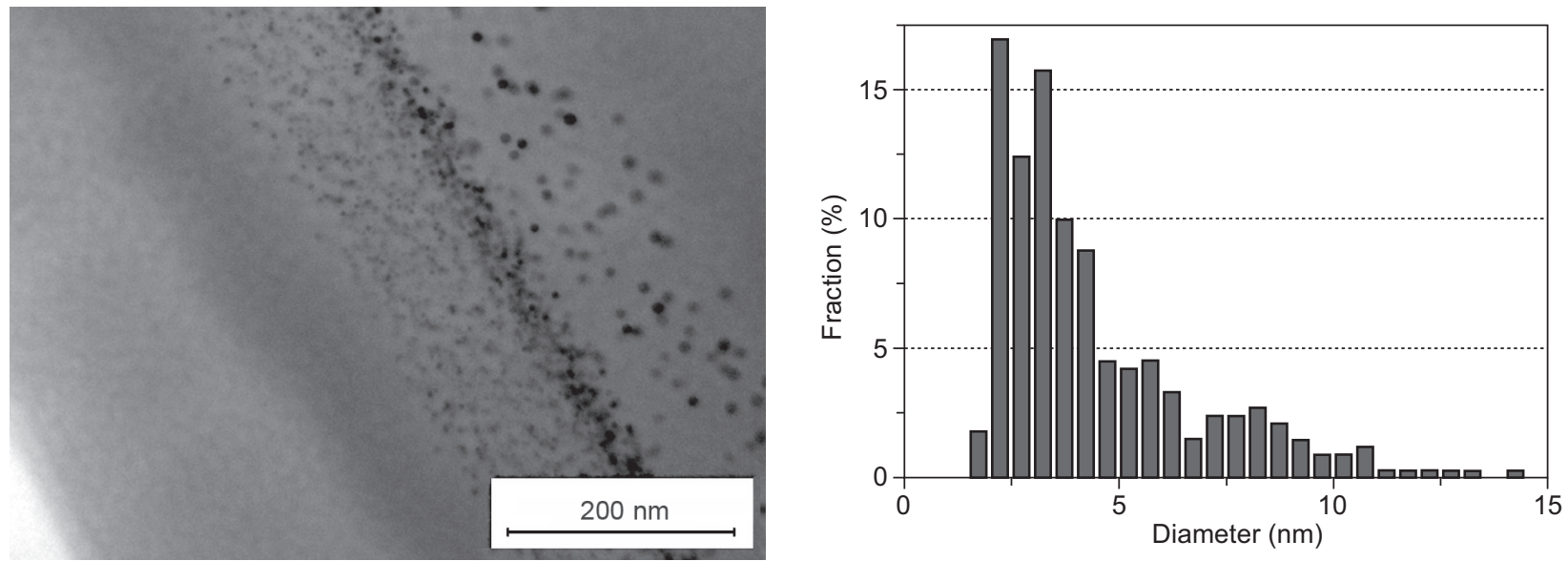

b) GIL49
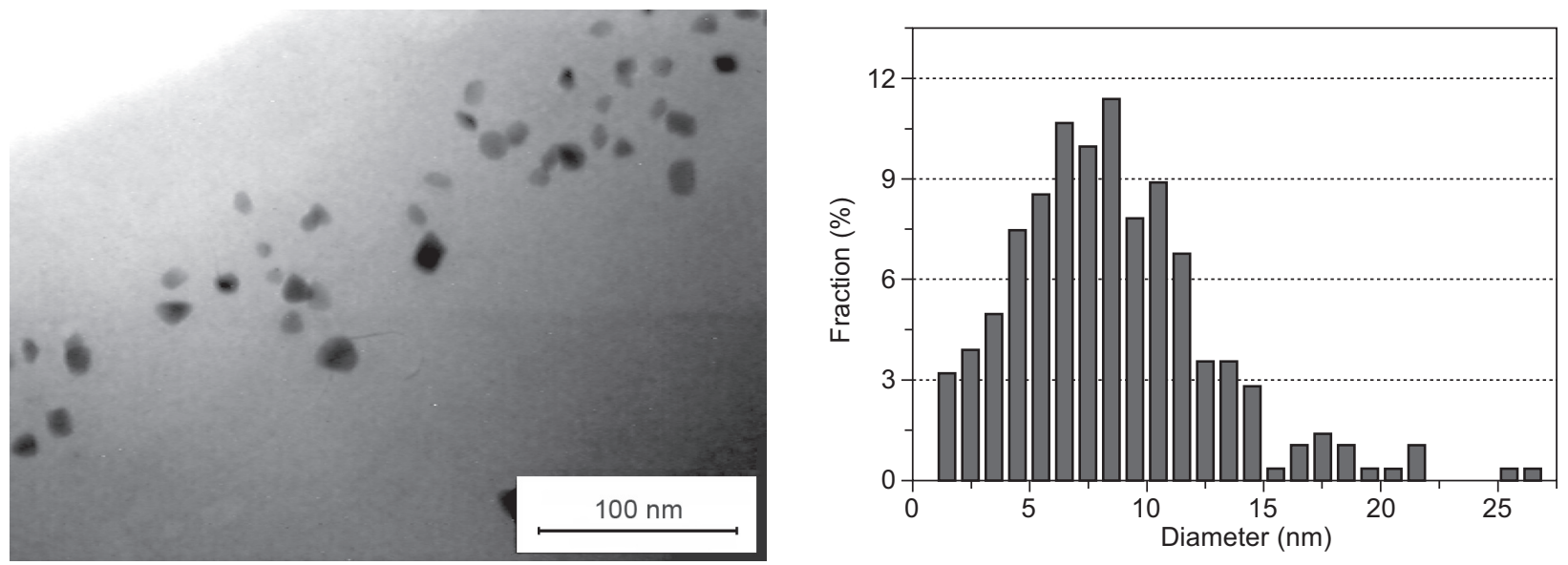

c) BK7.

Figure 3. TEM images of Au implanted into various silicate glasses and the statistical distribution of the size of the gold nanoparticles: a) glass B, b) GIL49; c) BK7.

annealing temperature if it is close to the transformation temperature $T_{\mathrm{g}}$ of the particular glass. It is a well-known fact that the main changes of the glass network occur especially in the vicinity of the $T_{\mathrm{g}}$. The BK7 was the only glass that was annealed above the transformation temperature $\left(T_{\mathrm{g}}\right.$ is approx. $\left.560^{\circ} \mathrm{C}\right)$. The formation of a brand-new glass network, entirely different from the original one, was probably a result of the annealing of BK7.

The remaining three glasses were annealed around or below their transformation temperature. As the $T_{\mathrm{g}} \mathrm{S}$ of those glasses are different, the course of the recovery was not the same either. Consequently, we could notice the differences with the concentration profile depth of 
gold and the sizes of the nanoparticles. The transformation temperature increases in the order BK $7 \rightarrow 600^{\circ} \mathrm{C}$ $\sim$ GIL49 $\rightarrow$ glass $\mathrm{B} \rightarrow$ silica glass. The experiment confirmed that the greater was the difference of the annealing temperature from the $T_{\mathrm{g}}$, the slower was the process of the recovery of the glass matrix (i.e., the rate, or the intensity, of the new bond formation). This may also explain why no gold nanoparticles were detected in the silica glass and only small particles were detected in a broad layer in the glass B. During annealing of the glass B, new bonds were created to a much lesser extent (as compared with a similar process in the BK7 glass), which probably led to an easier migration of the Au in the glass matrix, thus lowering its local concentration. After the implantation, the glass GIL49 was strongly damaged in comparison with the glass B or glass BK7 [22]. As a consequence, during annealing of GIL49, new bonds were formed to a greater extent and simultaneously the gold atoms migrated through the glass matrix and created nanoparticles of various sizes.

\section{CONCLUSION}

In this study, significant relations between the structure of glass, the migration of the implanted ions and the formation of metal nanoparticles in glasses during post-implantation annealing were found. After applying the $\mathrm{Au}^{+}$-ion implantation with energy of 1.7 $\mathrm{MeV}$ into different types of silicate glasses, it was demonstrated that the implanted-ion range depends primarily on the density of glass and, to a lesser extent, also on the structure of glass. In accordance with the previous results, it was confirmed that the projected range is shorter in glasses with higher cross-linking as well as when higher implantation energy is employed. Moreover, the shape, the size and the distribution of nanoparticles are strongly influenced by the current temperature of the annealing in the sense that the bigger the divergence of the annealing temperature from the transformation temperature of the particular glass is, the smaller are the forming nanoparticles and vice versa.

\section{Acknowledgements}

The research has been realized at the CANAM (Center of Accelerators and Nuclear Analytical Methods LM 2015056) infrastructure and has been supported by project GA 15-01602S and specific university research (MSMT 20-SVV/2016). M.J. acknowledges financial support by the Czech Science Foundation under the project 14-36566G.

\section{REFERENCES}

1. Chakraborty P. (1998): Metal nanoclusters in glasses as non-linear photonic materials. Journal of Materials Science, 33, 2235-2249. doi:10.1023/A:1004306501659

2. Palpant B. (2006). Third-Order Nonlinear Optical Response of Metal Nanoparticles, in Papadopoulos M.G., Sadlej A.J., Leszczynski J. (Eds.): Non-Linear Optical Properties of Matter. Springer. pp 461-508. doi:10.1007/14020-4850-5

3. Compton D., Cornish L., Lingen E. (2003): The third order nonlinear optical properties of gold nanoparticles in glasses, Part I and II. Gold Bulletin, 36, 10-16 and 51-58. doi:10.1007/BF03214860 and 10.1007/BF03214869

4. Daniel M.-C., Astruc D. (2004): Gold Nanoparticles: Assembly, Supramolecular Chemistry, Quantum-SizeRelated Properties, and Applications toward Biology, Catalysis, and Nanotechnology. Chemical Review, 104, 293-346. doi:10.1021/cr030698+

5. White C.W., Withrow S. P., Meldrum A., Budai J. D., Hembree D. M., Zhu J. G., Henderson D. O., Prawer S. (1998): Optical Properties Of Si Nanocrystals Formed In $\mathrm{SiO}_{2}$ By Ion Implantation. MRS Proceedings, 507, 249254. doi:10.1557/PROC-507-249

6. Withrow S. P., White C.W., Meldrum A., Budai J. D., Hembree D. M., Barbour J. C. (1999): Effects of hydrogen in the annealing environment on photoluminescence from Si nanoparticles in $\mathrm{SiO}_{2}$. Journal of Applied Physics, 86, 396-401. doi:10.1063/1.370699

7. Bach H., Neuroth N. (1998). The Properties of Optical Glass. $1^{\text {st }}$ ed. Springer.

8. Arnold G.W. (1975): Near-surface nucleation and crystallization of an ion-implanted lithia-alumina-silica glass. Journal of Applied Physics, 46, 4466-4473. doi:10.1063/ 1.321422

9. Mazzoldi P., Arnold G. W., Battaglin G., Bertoncello R., Gonella F. (1994): Peculiarities and application perspectives of metal-ion implants in glasses. Nuclear Instruments and Methods in Physics Research Section B, 91, 478-492. doi:10.1016/0168-583X(94)96273-1

10. Mazzoldi P., Arnold G.W., Battaglin G., Gonella F., Haglund R.F. (1996): Metal Nanocluster Formation by Ion Implantation in Silicate Glasses: Nonlinear Optical Applications. Journal of Nonlinear Optical Physics \& Materials, 5, 285-330. doi:10.1142/S0218863596000209

11. Battaglin G., Boscolo-Boscoletto A., Mazzoldi P., Meneghini C., Arnold G. W. (1996): Gold nanocluster formation in silicate glasses by low fluence ion implantation and annealing. Nuclear Instruments and Methods in Physics Research Section B, 116, 527-530. doi:10.1016/ 0168-583X(96)00101-2

12. Wood R.A., Townsend P.D., Skelland N.D., Hole D.E., Barton J., Afonso C.N. (1993): Annealing of ion implanted silver colloids in glass. Journal of Applied Physics, 74, 5754-5756. doi:10.1063/1.354194

13. Mazzoldi P., Arnold G.W. (1987). Ion Beam Modification of Insulators. Elsevier.

14. Magruder III R.H., Yang L., Haglund R.F. Jr., White C.W., Yang L., Dorsinville R., Ralfano R. (1993): Optical properties of gold nanocluster composites formed by deep ion implantation in silica. Applied Physics Letters, 62, 1730-1732. doi:10.1063/1.109588

15.Ila D., Williams E.K., Sarkisov S., Smith C.C., Poker D.B., 
Hensley D.K. (1998): Third order optical nonlinearity of colloidal metal nanoclusters formed by $\mathrm{MeV}$ ion implantation. Nuclear Instruments and Methods in Physics Research Section B, 141, 289-293. doi:10.1063/1.109588

16. Arnold G.W., Borders J.A. (1977): Aggregation and migration of ion-implanted silver in lithia-aluminasilica glass. Journal of Applied Physics, 48, 1488-1496. doi: $10.1063 / 1.323867$

17.Mazzoldi P., Caccavale F., Cattaruzza E., Chakraborty P., Tramontin L., Boscolo-Boscoletto A., Bertoncello R., Trivillin F., Battaglin G., Arnold G.W. (1994): Colloid formation in copper-implanted fused silica and silicate glasses. Nuclear Instruments and Methods in Physics Research Section B, 91, 505-509. doi:10.1016/0168583X(94)96275-8

18.P. Mazzoldi, L. Tramontin, A. Boscolo-Boscoletto, G. Battaglin, G.W. (1993): Arnold Substrate effects in silverimplanted glasses. Nuclear Instruments and Methods in Physics Research Section B, 80-81, 1192-1196. doi:10.1016/0168-583X(93)90764-W

19. Stepanov A.L. (2011): Nonlinear optical properties of implanted metal nanoparticles in various transparent matrixes: a review. Reviews on Advanced Materials Science, 27, 115-145.

20. Sasai J., Hirao K. (2001): Relaxation behavior of nonlinear optical response in borate glasses containing gold nanoparticles.AppliedPhysics, 89, 4548-4553.doi:10.1063/ 1.1355279

21.Svecova B., Nekvindova P., Mackova A., Malinsky P., Kolitsch A., Machovic V., Stara S., Mika M., Spirkova J. (2010): Study of $\mathrm{Cu}^{+}, \mathrm{Ag}^{+}$and $\mathrm{Au}^{+}$ion implantation into silicate glasses. Journal of Non-Crystalline Solids, 356, 2468-2472. doi:10.1016/j.jnoncrysol.2010.03.031
22.Nekvindova P., Svecova B., Stanek S., Vytykacova S., Mackova A., Malinsky P., Machovic V., Spirkova J. (2015): The Raman Spectroscopy use for monitoring of change in the glass structure of the thin layers caused by ion implantation. Ceramics-Silikáty, 59, 187-193.

23. Ashby M.F., Ferreira P.J., Schodek D.L. (2009). Nanomaterials, Nanotechnologies and Design: An Introduction for Engineers and Architects. $1^{\text {st }}$ ed. Butterworth-Heinemann.

24.Husinsky W., Ajami A., Nekvindova P., Svecova B., Pesicka J., Janecek M. (2012): Z-scan study of nonlinear absorption of gold nano-particles prepared by ion implantation in various types of silicate glasses. Optics Communications, 285, 2729-2733. doi:10.1016/j.optcom.2012.01.044

25.Ziegler J.F., Stopping and Range of Ions in Matter: SRIM -2008 , www.srim.org.

26. Malinsky P., Mackova A., Bocan J., Svecova B., Nekvindova P. (2009): Au implantation into various types of silicate glasses. Nuclear Instruments and Methods in Physics Research Section B, 267, 1575-1578. doi:10.1016/j.nimb.2009.01.161

27. Malinský P., Macková A., Nekvindová P., Švecová B., Kormunda M., Kolitsch A. (2011): The Characterisation of Silicate Glasses Implanted with $\mathrm{Ag}^{+}$Ions. AIP Conference Proceedings, 1412, 327-334. doi:10.1063/1.3665331

28. Malinsky P., Mackova A., Hnatowicz V., Khaibullin R. I., Valeev V. F., Slepicka P., Svorcik V., Slouf M., Perina V. (2012): Properties of polyimide, polyetheretherketone and polyethyleneterephthalate implanted by $\mathrm{Ni}$ ions to high fluences. Nuclear Instruments and Methods in Physics Research Section B, 272, 396-399. doi:10.1016/j. nimb.2011.01.109 